\title{
Clinical, electroretinographic and histomorphometric evaluation of the retina in sheep with natural scrapie
}

\author{
Alain Regnier ${ }^{1 *}$, Olivier Andreoletti ${ }^{2}$, Olivier Albaric ${ }^{2}$, Delphine Cayez Gruson ${ }^{1}$, François Schelcher ${ }^{2}$ and \\ Pierre-Louis Toutain ${ }^{1}$
}

\begin{abstract}
Background: The retina is part of the diencephalon in a peripheral location and may be involved in prion diseases. Retinal function and structural changes were assessed in naturally scrapie-affected red face Manech ewes presenting the classical signs of the disease, and clinically healthy age-matched subjects for controls. Ophthalmic examination was done prior to electroretinography (ERG), which was carried out under conditions that allowed photopic and scotopic activities to be assessed. Histomorphometry of the inner and outer retinal layers was performed post-mortem, and retinas were also examined for evidence of abnormal prion protein ( $P r P^{S c}$ ) accumulation and glial fibrillary acidic protein (GFAP) upregulation as a marker of gliosis. Scrapie status was determined by examination of brain tissue

Results: Ocular reflexes and ophthalmoscopy did not reveal any difference between scrapie affected and control animals. Although the light-and dark-adapted ERG responses of both rod-and cone-mediated functions had a similar waveform in scrapie-affected and control sheep, a significant reduction in the amplitude of the ERG a-and b-waves was observed in affected animals compared to controls. These functional alterations were correlated with a substantial loss of cells in the outer nuclear layer (ONL), lengthening and disorganization in photoreceptor segments, and substantial reduction in cellularity and thickness of the inner nuclear layer (INL). The degenerative changes in the INL and ONL were most marked in the central and paracentral areas of the scrapie retinas, and were accompanied in all scrapie retinas by $\operatorname{PrP}^{\mathrm{Sc}}$ deposition in the ganglion cell and synaptic layers. GFAP immunoreactivity was mainly increased in the ganglion cell and inner plexiform layers.

Conclusions: No appreciable fundoscopic changes were observed in the scrapie-affected ewes although reproducible changes in retinal function as measured by ERG were observed in these animals. The alterations in the receptoral and post-receptoral pathways corresponded to the degenerative lesions observed in the ONL and INL of the scrapie retinas. The retinal degeneration was associated with prion protein infectivity which presumably spread via the optic nerve.
\end{abstract}

Keywords: electroretinography, prion, retina, scrapie, sheep

\section{Background}

Transmissible spongiform encephalopathies (TSE), or prion diseases, are fatal neurodegenerative diseases with a very long incubation period which include kuru and Creutzfeld-Jacob disease (CJD) in humans, bovine spongiform encephalopathy (BSE), scrapie in sheep and goats and transmissible mink encephalopathy [1,2].

\footnotetext{
* Correspondence: a.regnier@envt.fr

'UMR 181 Physiopathologie et Toxicologie Expérimentales, INRA, Ecole Nationale Vétérinaire, 23 chemin des Capelles, B.P. 87614, 31076 Toulouse Cedex 3, France

Full list of author information is available at the end of the article
}

Accumulation of an abnormal isoform $\left(\mathrm{PrP}^{\mathrm{Sc}}\right)$ of a normal cellular protein $(\mathrm{PrP})$ in affected host tissues is considered a disease hallmark, and its deposition in tissues correlates with infectivity $[3,4]$. According to the prion hypothesis, $\operatorname{Pr} \mathrm{P}^{\mathrm{Sc}}$ itself is thought to be the causative agent of TSE [5].

The retina is a part of the diencephalon in a peripheral location [6], and its involvement in the TSE context was initially explored in rodent models of CJD [7] and scrapie [8-11] before being documented in humans affected with the sporadic and variant CJD [12-14].
C Biomed Central

() 2011 Regnier et al; licensee BioMed Central Ltd. This is an Open Access article distributed under the terms of the Creative Commons Attribution License (http://creativecommons.org/licenses/by/2.0), which permits unrestricted use, distribution, and reproduction in any medium, provided the original work is properly cited. 
Previous studies assessing the retinal changes in sheep with natural scrapie have been performed, but without morphometric analysis [15,16], and information on the activity of the retina in scrapie-infected sheep is presently limited to one case report [17].

As a follow-up to our initial report [18], this paper further defines the functional and structural abnormalities of the retina in sheep with natural scrapie using ophthalmic, electroretinographic, morphometric, histopathological and immunohistochemical examinations.

\section{Methods}

\section{Animals}

Seventeen scrapie-affected red face Manech ewes at various stages of disease progression were collected from different field scrapie-infected flocks. They were between 1 and 3 years old. Clinical diagnosis relied on observation of classical scrapie signs (i.e. pruritus, behavioral changes, tremor, and locomotor incoordination). Six clinically healthy age-matched red face Manech ewes were used as controls. All animals were eventually subjected to euthanasia and the definitive scrapie status was determined by examination of brain tissue. All animal experiments have been performed in compliance with our institutional and national guidelines in accordance with the European Community Council directive 86/ 609/EEC. The experimental protocol was approved by the INRA Toulouse/ENVT ethics committee.

\section{Physical and electrophysiological examinations}

An ocular examination including visual testing by the menace response and pupillary light reflexes, as well as indirect and direct ophthalmoscopy after pupil dilation with topical $0.5 \%$ tropicamide was performed. For the full-field electroretinogram (ERG) recordings, the ewes were placed in metabolism cages, and kept with a background room illumination of $27 \mathrm{~cd} \cdot \mathrm{m}^{-2}$ (photometer S371R Optical Power Meter, Graseby Optronics, Orlando, FL, USA) for 2 hours. The animals were then anesthetized by intramuscular injection of ketamine (11 $\mathrm{mg} / \mathrm{kg})$ and xylazine $(0.22 \mathrm{mg} / \mathrm{kg})$. They were positioned in sternal recumbency with the head immobilized in a headrest by means of padded supports and straps. The muzzle was held horizontally, and the upper eyelid of both eyes was drawn back by placing 2 interrupted vertical mattress sutures. After topical anesthesia with 0.5\% oxybuprocaine, a stainless steel recording needle was positioned subconjunctivally, $2-3 \mathrm{~mm}$ posterior to the limbus, at the 12 o'clock position. The reference electrode was placed subcutaneously at the base of the ear and the animal was grounded by another electrode placed subcutaneously in the occipital region. The cornea was kept moist by periodic topical administrations of a $0.1 \%$ hyaluronate sodium solution. The ERG responses were elicited simultaneously from both eyes, with stimuli of $200-\mu$ s duration generated by white strobe flashes. The flash units (Varéclat ${ }^{\mathbb{R}}$, Alvar Electronic, Montreuil, France) were positioned $5 \mathrm{~cm}$ from each eye on the visual axis. The signals were fed back to an ERG recording system (MP3, ECEM électronique et informatique médicale, Ozoir-la-Ferrière, France), using analog bandpass filtering from 1 to $300 \mathrm{~Hz}$ in conjunction with $60-\mathrm{Hz}$ notch filtering. For each recording, 8 consecutive responses were averaged to stimuli presented at $2 \mathrm{~Hz}$. After the 2 hours of light adaptation, an initial cone-dominant response was elicited with unattenuated white light stimuli of $1.7 \mathrm{~cd} \cdot \mathrm{s}^{-1} \cdot \mathrm{m}^{-2}$. The animals were then placed in the dark, and rod-dominant responses were obtained 1, 5, 10 and 15 minutes after adaptation to complete darkness, using a blue filter (Kodak Wratten 47B) and a neutral density filter (1.0 ND) in front of each flash. After 18 minutes of dark adaptation, a flash ERG response including both rod and cone components was recorded to unattenuated white flashes. Each recording session took about 20 minutes and during this period no additional anesthesia was applied. The amplitude and implicit time of the initial negative (a-wave) and/or the subsequent positive (b-wave) peak of the response were measured in the normal way. The amplitude of the a-wave represented the voltage difference between the baseline level and the peak of the first negative deflection, whereas the amplitude of the b-wave represented the voltage difference between the peak of the wave and the preceding trough [19]. Implicit times of the a-and b-waves were measured from the time of the light stimulus presentation to the peak of each wave [19].

\section{Histomorphometry}

Within 1 to 7 days after ERG recording, animals were killed with intravenous injection of sodium pentobarbital followed by exsanguination. Eyes from the 6 healthy and 13 scrapie-affected subjects were prepared for light microscopic and immunohistochemical examination. In these animals, the eyes were enucleated rapidly postmortem, immersed in Zenker's solution for 2 hours, then washed in tap water for 2 hours and placed in $80^{\circ}$ alcohol solution. After bisecting each eye along the vertical meridian, the two halves of the globe were dehydrated and paraffin embedded. Sections $2 \mu \mathrm{m}$ thick including the optic nerve were made, dried overnight at $56^{\circ} \mathrm{C}$, deparaffinized and rehydrated before being stained with haematoxylin-eosin. They were blind coded, and morphometric investigation of the retina was made by two observers (OA and OA) at three locations, as previously reported [8]. They included the central retina, immediately adjacent to the dorsal edge of the optic disc, the paracentral retina 
halfway between the optic disc and ora ciliaris retinae, and the peripheral retina immediately adjacent to the ora ciliaris retinae. At each location, the thickness of the photoreceptor segments (combined outer and inner segment length), outer nuclear layer (ONL), outer plexiform layer (OPL), inner nuclear layer (INL) and inner plexiform layer (IPL) was measured at $\mathrm{x} 400$ magnification, using a digital image analyzer (Visiolab 1000, Meylan, France). The thickness of each individual retinal layer was determined in pixels using an internal standard with an arbitrarily fixed pixel graduation. The relative number of cells present in each retina was also estimated at $\mathrm{x} 400$ magnification by counting the nuclei in ONL and INL respectively. For each predetermined site of the retina (central, paracentral and peripheral), ONL and INL cell densities from each eye were counted within three fields of $250 \mu \mathrm{m}$ wide and these data were computed to a mean value.

\section{Immunohistochemistry}

The tissue sections including the optic nerve area submittted to immunohistochemistry, were first denaturated with 98 per cent formic acid for 30 minutes at room temperature and then autoclaved for 20 minutes at $121^{\circ}$ C. After endogenous peroxidase was quenched with $\mathrm{H}_{2} \mathrm{O}_{2}$ in methanol, the slides were blocked with $20 \%$ normal goat serum in TBS for $20 \mathrm{~min}$ and incubated with the primary antibody for $60 \mathrm{~min}$ at room temperature, followed by 30-min incubations first with biotinylated goat anti-rabbit immunoglobulins or goat antimouse immunoglobulins secondary antibodies diluted $1: 100$ and then with the streptavidin-peroxidase complex diluted 1:100. The reaction was developed using 3,3'-diaminobenzidine (ChemMateTM Detection Kit Peroxidase/DAB, K 5001, DAKO, Copenhagen, Denmark). Each step was followed by three 5 -min washes using a $1 \%$ skimmed milk-0.05\% Tween 20 in TBS. Finally, tissue sections were counterstained with Mayer's haematoxylin. $\operatorname{PrP}^{\mathrm{Sc}}$ immunolabelling was carried out using a primary monoclonal antibody 2 G11 raised in mice against recombinant peptide fragment R154-R171 of ovine PrP protein (generously provided by INRA VIM, Jouy-en-Josas, France) and diluted 1:1000 in ascite. The expression of the glial fibrillary acidic protein (GFAP), as a reactive marker of Müller cells gliosis, was determined using a primary polyclonal antibody, raised in rabbits against bovine GFAP (GFAP 0761, Dako, Copenhagen, Denmark).

\section{Confirmation of disease status}

For each animal, the brain was removed, stored in $10 \%$ formalin, and processed for light microscopic and immunohistochemical examination of the obex and midpons as previously described [20].

\section{Statistical analyses}

Nested analysis of variance with unequal sample sizes examined pooled data from both eyes for the significance of ERG response differences between diseased and control animals [21]. For the morphometric evaluation of the retina, three measurements of each variable were made in every location and averaged for statistical analysis. As contralateral eyes were not considered to be independent of each other, the statistical analyses were performed using information from one eye randomly chosen for each ewe. For each variable, the comparison between the diseased and control groups was made by using a one-way analysis of variance. For each analysis, the residuals from the fitted model were graphically assessed; in each case the standard assumptions of normality, constant variance and randomness were confirmed. Statistical significance was defined as $\mathrm{p}$ value $<0.05$.

\section{Results}

In the 17 clinically suspect ewes the diagnosis of scrapie was confirmed by observation of vacuolar changes and $\mathrm{PrP}^{\mathrm{Sc}}$ accumulation in the brainstem. In contrast, brain tissues from the clinically healthy sheep showed no spongiform vacuolation, and no $\mathrm{PrP}^{\mathrm{Sc}}$ deposits were detected in their lymphoid tissue and central nervous system.

During ocular examination, no mydriasis was detected in the scrapie-affected sheep and normal pupillary light reflexes were observed in both groups of animals. The palpebral and corneal reflexes were normal in all affected sheep, but inconsistent menace responses were observed in 1 control and 3 diseased sheep. No ophthalmoscopic evidence of fundic lesions was apparent in either the 17 affected ewes or the control animals.

The light-adapted ERG responses were recorded from all animals but the mean amplitudes of the cone-dominant $\mathrm{a}$-and $\mathrm{b}$-waves were significantly lower $(\mathrm{p}<0.01)$ in scrapie affected ewes compared with controls (Table 1). Implicit time of light-adapted a-and b-wave responses was not significantly different between control and affected ewes (a-wave: $13.1 \pm 0.7 \mathrm{~ms}$ vs $13.7 \pm 2.1$ ms, p > 0.05; b-wave: $29.6 \pm 0.9 \mathrm{~ms}$ vs $28.4 \pm 2.1 \mathrm{~ms}, \mathrm{p}$ $>0.05)$. Following dark adaptation and using blue light stimulation, the a-wave of the rod-dominant ERG responses was not recordable in both the control and affected animals. With the adapting time duration the mean rod-dominant b-wave amplitude increased gradually in both groups of animals but remained significantly lower $(\mathrm{P}<0.01)$ in affected than in healthy subjects for each time point (Table 1 ). The latencies of the conemediated b-waves were not statistically different between the control and affected animals at each time point. Mixed rod-cone responses to dark-adapted 
Table 1 Results of the electroretinographic recordings

\begin{tabular}{|c|c|c|c|c|c|}
\hline \multirow[t]{2}{*}{ Stimulus and adaptation } & \multirow[t]{2}{*}{ Time $(\min )$} & \multicolumn{2}{|c|}{ a-wave amplitude $(\mu \mathrm{V})$} & \multicolumn{2}{|c|}{ b-wave amplitude $(\mu \mathrm{V})$} \\
\hline & & Control & Scrapie & Control & Scrapie \\
\hline$w L$ & 0 & $87.9 \pm 10.2$ & $70.6 \pm 13.9^{* *}$ & $342.1 \pm 62.3$ & $224.8 \pm 86.9^{* *}$ \\
\hline $\mathrm{blD}_{1}$ & 1 & & & $112.7 \pm 25.8$ & $48.9 \pm 28.0^{* *}$ \\
\hline $\mathrm{blD}_{2}$ & 5 & & & $271.1 \pm 36.6$ & $118.7 \pm 49.9^{* *}$ \\
\hline $\mathrm{blD}_{3}$ & 10 & & & $310.5 \pm 31.1$ & $169.6 \pm 55.8^{* *}$ \\
\hline $\mathrm{blD}_{4}$ & 15 & & & $343.2 \pm 35.2$ & $189.9 \pm 59.1^{* *}$ \\
\hline $\mathrm{wD}_{5}$ & 18 & $108.5 \pm 19.2$ & $88.1 \pm 18.4^{*}$ & $257 \pm 43.0$ & $238.2 \pm 100.7$ \\
\hline
\end{tabular}

Electroretinographic $(E R G)$ response amplitudes (mean \pm SD) obtained under various stimulus conditions in unaffected control and naturally scrapie-affected sheep. wL: white light stimuli on light-adapted eyes; bID: blue light stimuli on dark-adapted eyes; wD: white light stimuli on dark-adapted eyes. Level of significance ${ }^{*} P<0.05,{ }^{*} P<0.01$

unattenuated white stimuli were recorded from all diseased ewes. The mean amplitude of the a-wave was significantly reduced $(\mathrm{p}<0.05)$ in these animals compared with controls (Table 1). However, the difference in the b-wave amplitude between the two groups was not significantly different $(\mathrm{p}>0.05)$ because of the large variability of the results in affected ewes (Table 1 ). The darkadapted white flash stimuli induced no significant difference $(p>0.05)$ in implicit time between control and affected sheep.

Light microscopic examination of the control eyes revealed no retinal abnormalities (Figure 1a). In all scrapie affected sheep, histological lesions of the retina were observed but with variable severity among subjects. In the outermost retina, the elongation and disorganization of the photoreceptor segments in the scrapie retinas (Figure $1 \mathrm{~b}$ ) resulted in a significant thickening of this layer $(\mathrm{p}<0.05)$ compared to the controls (Table 2). A multifocal accumulation of amorphous eosinophilic material between the photoreceptor outer segments and the retinal pigment epithelium, which corresponds to the subretinal space, was also observed in the affected animals (Figure 1c). The retinal pigment epithelium appeared histologically normal. In contrast, a widespread decrease in thickness of the ONL was found in the retina of affected sheep, along with a reduction in the number of photoreceptor nuclei. These changes were more marked in the central and paracentral regions than in the peripheral retina (Tables 2). Large perinuclear spaces suggested loss of cytoplasm and cell shrinkage. Presence of occasional pyknotic nuclei in the ONL provided further evidence of photoreceptor cell degeneration. Displacement of photoreceptor nuclei in the photoreceptor inner segment layer was sometimes observed (Figure 1b). In retinas from scrapie-affected animals, the changes in the OPL manifested as an irregular thickness with a significant thinning in the central and paracentral areas of the retina (Table 2). This was associated with a clear disorganisation of OPL in about half of the specimens. A significant thinning in the INL was observed in the retina of the scrapie-affected animals (Table 2) in association with a significant decrease in nuclei density (Table 3), and a moderate cellular infiltration by macrophage-like cells. There was no statistically significant difference between the IPL of scrapie and control retinas (Table 2), but scattered areas of vacuolation were observed in the scrapie retinas displaying the most severe morphological changes. Because the ganglion cell density varied considerably throughout the control retinas, comparative morphometric investigation could not be done. However, there was no apparent morphologic difference in this retinal layer between the two animal groups.

No $\operatorname{PrP}^{\mathrm{Sc}}$ immunolabelling was observed in the retinas of the control sheep but, conversely, $\mathrm{PrP}^{\mathrm{Sc}}$ deposits were observed in the neuroretina of all the scrapie-affected cases and were more prominent in the central area of the retina. However, in animals with the strongest positive reaction, the deposits were more homogenously distributed throughout the retina. $\mathrm{PrP}^{\mathrm{Sc}}$ deposits were observed in the ganglion cell layer, IPL and OPL of each affected retina, and in the inner segments of the photoreceptor layer of some of them (Figure 1c). The immunostaining took the form of a brownish granular pattern in the plexiform layers of the neuroretina and perikarya of the ganglion cells (Figure 1c). Positive $\operatorname{PrP}^{\mathrm{Sc}}$ immunostaining was not evident within the optic nerve or any ocular tissues other than the neuroretina. Compared to the control retinas (Figure 1d), an increased expression of GFAP was observed in the IPL and ganglion cell layer from all scrapie retinas, indicating Müller cell gliosis (Figures 1e). In the cases where $\operatorname{PrP}^{\mathrm{Sc}}$ accumulation was the most intense, increased GFAP immunoreactivity was also present in the INL and ONL.

\section{Discussion}

Our results demonstrate that electrophysiological and histopathological changes indicative of retinal degeneration were present in all the scrapie-affected sheep examined for the current investigation. Nevertherless, no behavioral or neuro-ophthalmologic changes were found that were indicative of visual impairment in these 


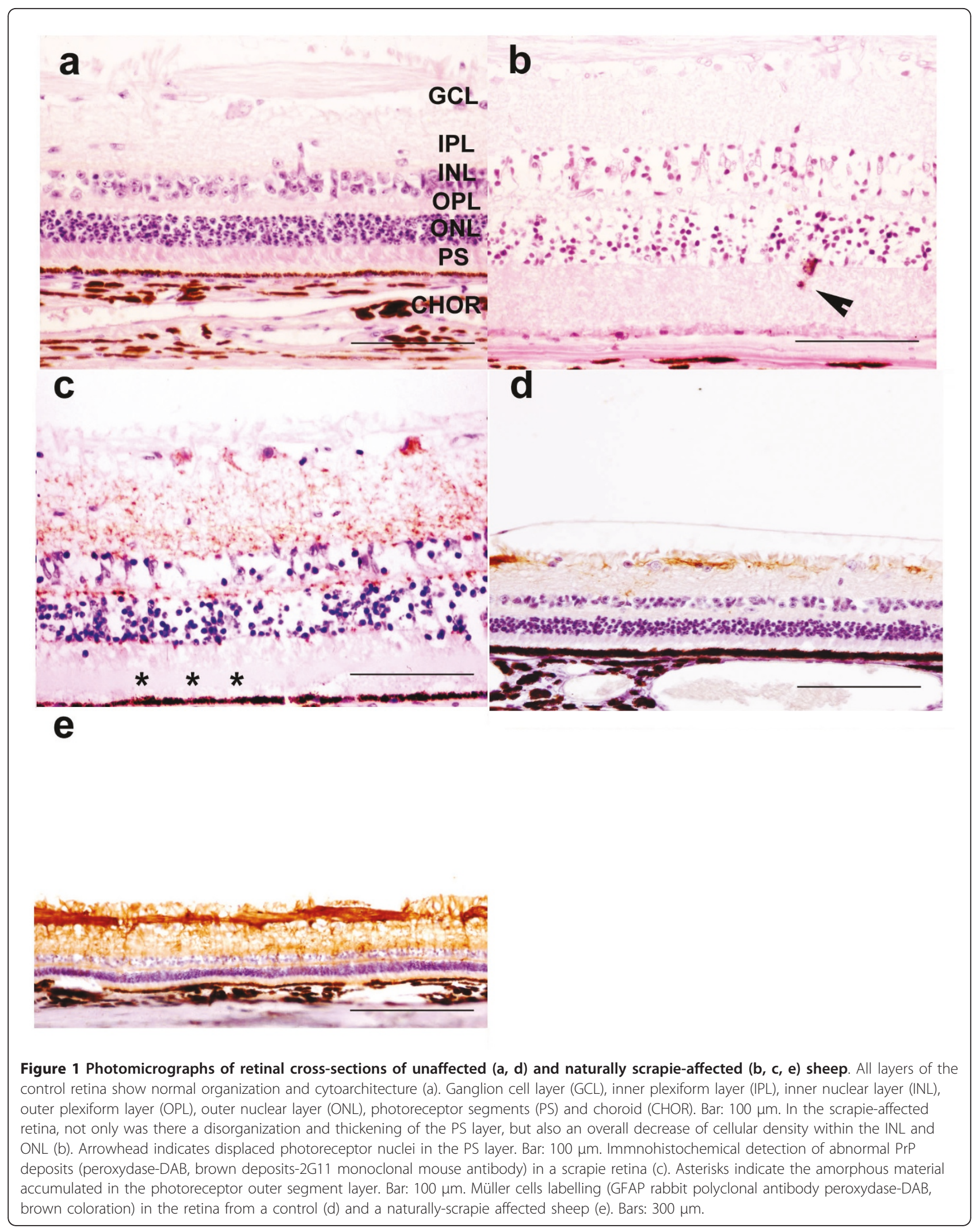


Table 2 Average thickness of retinal layers

\begin{tabular}{ccccccc}
\hline \multirow{2}{*}{ Layer } & \multicolumn{2}{c}{ Central retina } & \multicolumn{2}{c}{ Paracentral retina } & \multicolumn{2}{c}{ Peripheral retina } \\
\cline { 2 - 6 } & Control & Scrapie & Control & Scrapie & Control & Scrapie \\
\hline Photoreceptor segments & $13.5 \pm 1.1$ & $17.0 \pm 4.3^{* * *}$ & $13.8 \pm 0.7$ & $18.3 \pm 3.6^{* * *}$ & $14.6 \pm 1.9$ & $18.2 \pm 3.1^{* * *}$ \\
Outer nuclear & $28.6 \pm 1.7$ & $24.0 \pm 6.0^{*}$ & $27.2 \pm 0.9$ & $24.4 \pm 3.6^{*}$ & $24.4 \pm 1.6$ & $24.3 \pm 3.9$ \\
Outer plexiform & $7.2 \pm 0.5$ & $5.9 \pm 1.7^{*}$ & $7.8 \pm 0.7$ & $7.5 \pm 2.7^{* *}$ & $8.4 \pm 1.2$ & $7.9 \pm 3.0^{*}$ \\
Inner nuclear & $20.7 \pm 1.5$ & $17.1 \pm 3.1^{* *}$ & $19.7 \pm 1.3$ & $17.1 \pm 2.8^{*}$ & $19.9 \pm 1.6$ & $17.6 \pm 2.9^{* * *}$ \\
Inner plexiform & $30.0 \pm 3.1$ & $32.9 \pm 6.5$ & $33.5 \pm 2.0$ & $32.7 \pm 4.6$ & $32.5 \pm 2.3$ & $31.9 \pm 5.6$ \\
\hline
\end{tabular}

Thickness of the retinal layers (in pixels) in unaffected control and naturally scrapie-affected sheep. Data are expressed as mean \pm SD. Level of significance *P $<$ $0.05,{ }^{* *} \mathrm{P}<0.01,{ }^{* * *} \mathrm{P}<0.001$.

animals. This is in agreement with recent reports in which deterioration of vision is never mentioned as a presenting sign of typical and atypical cases of natural ovine scrapie [20,22-25]. Differentially, blindness appears to be a major clinical feature in other ovine neurodegenerative diseases such as ceroid-lipofuscinosis [26] or Helychrysum argyrosphaerum poisoning [27]. The ocular fundus examination was unremarkable in our affected animals and did not reveal the rare and typical raised, roughly oval, blister-like areas previously described in two cases, which presumably result from accumulation in the subretinal space of the amorphous material noted morphologically [15]. Such ophthalmoscopic characteristics have never been described in other experimental or spontaneous TSE cases [7-9,11,13,14,28] and were not identified in our affected animals, possibly because the accumulation of the amorphous material, as seen histologically, was less pronounced in these animals than in the two cases reported by Barnett \& Palmer [15].

Since the ovine retina is of mixed rod and cone type [29], the ERG responses obtained in our sheep were characterized by an obvious a-wave and a fast b-wave in light-adapted condition, and by a non recordable a-wave and a slow b-wave which increased in amplitude during dark adaptation [19]. In the control eyes, these responses were in agreement with those previously reported in healthy sheep studied under different protocols [30-32]. In the scrapie-affected animals, the significant reduction in the a-wave amplitude observed under photopic and scotopic conditions (about 20\% compared to the controls) was indicative of abnormalities in the photoreceptor layer involving both the cone and rod mechanisms [33]. The degree of ERG a-wave amplitude reduction agreed well with the amount of morphologically determined photoreceptor nuclei loss in the ONL. The rod system dysfunction was especially demonstrated in recordings of the responses to blue light during the 15 minutes of dark adaptation, which showed a $45-56 \%$ reduction in the response amplitude when compared with controls. The reduction in amplitude of the bwave, which represents contribution of the bipolar and Müller cells [34,35], was consistent with the changes of the bipolar cell layer noted in the retinal histopathology of the affected animals. Similarly, the ERG abnormalities detected in humans with CJD are characterized by a more marked decrease in the b-wave than a-wave amplitude $[12,36]$. Despite the reduction in amplitude, both rod-and cone-derived responses retained basically normal waveform and implicit times. This result is somewhat surprising in light of the morphological lesions, but a similar situation has been observed in mice with experimental scrapie [11]. It indicates that both the photoreceptors and the post-receptor pathways retain a modicum of normal function [19,37-39] and is in agreement with the uneven distribution of the histological lesions in the retinas of our affected sheep, which probably left a sufficient number of functional retinal neurons.

Morphological changes representative of retinal degeneration and consistent with the ERG findings were observed in all scrapie-affected sheep in the current study. These histopathological lesions were associated

Table 3 Cell density measurement in ONL and INL

\begin{tabular}{ccccccc}
\hline \multirow{2}{*}{ Nuclei/field } & \multicolumn{2}{c}{ Central retina } & \multicolumn{2}{c}{ Paracentral retina } & \multicolumn{2}{c}{ Peripheral retina } \\
\cline { 2 - 6 } & Control & Scrapie & Control & Scrapie & Control & Scrapie \\
\hline $\begin{array}{c}\text { Outer nuclear } \\
\text { layer }\end{array}$ & $5.9 \pm 0.7$ & $4.7 \pm 1.1^{* *}$ & $5.8 \pm 0.6$ & $4.9 \pm 0.8^{*}$ & $5.3 \pm 0.9$ & $5.1 \pm 1.5$ \\
$\begin{array}{c}\text { Inner nuclear } \\
\text { layer }\end{array}$ & $1.5 \pm 0.2$ & $1.0 \pm 0.2^{* *}$ & $1.4 \pm 0.2$ & $1.0 \pm 0.2^{*}$ & $1.5 \pm 0.2$ & $1.3 \pm 0.4$ \\
\hline
\end{tabular}

Cell density measurement (mean \pm SD) in outer nuclear layer (ONL) and inner nuclear layer (INL) of retinas from unaffected control and naturally scrapie-affected sheep. In each of the three areas examined from each retina, the cell count was obtained by averaging the measurements made within three fields of $250 \mu \mathrm{m}$ wide and at $x 400$ magnification. Level of significance ${ }^{*} P<0.05,{ }^{* *} P<0.01$ 
with $\operatorname{PrP}^{\mathrm{Sc}}$ deposition in all of the cases and alterations in the retinal glia manifested as an increased expression of the intermediate filament GFAP. In a recent report, only $50 \%$ of sheep with signs of natural scrapie were found to have retinal degenerative lesions [16]. In our affected sheep, the multifocal accumulation of amorphous material within the subretinal space was less marked than in the two cases reported by Barnett and Palmer [15]. This material, composed of a complex lipid which is probably disintegrating outer segments [15], was associated with elongation and disorganization of the photoreceptor segments. These alterations were clearly a consequence of the photoreceptor degeneration that was also reflected by the reduction in thickness and cellularity of the ONL. A complete loss of photoreceptors similar to that described in the retinas of scrapieinfected mice $[9,11]$, and hamsters $[8,28]$ was never observed, but as with the rodent scrapie models, the ONL changes in the affected sheep were most severe in the central area and were occasionally associated with extrusion of photoreceptor nuclei to outer limiting membrane. The changes observed in the inner retinal layers of our affected sheep were characterized by a significant reduction in the cellular density of the central and paracentral INL, a slight influx of phagocytic cells (presumably macrophages) in the INL, and a few vacuolar changes within the IPL. Reduction in INL cellularity has been found in hamsters with experimental scrapie infection [8], and vacuolization of the plexiform and ganglion cell layers is a striking feature of the retinopathy associated with CJD in humans [12]. Although retinal degeneration is a recurrent pathological feature of scrapie, the morphological changes identified in the neurosensory retina of our affected sheep showed differences with previous observations made both in the rodent models $[8,9,11,28]$, and natural cases in sheep $[15,16]$. These discrepancies may reflect the species and breed of the host and/or the biological properties of the scrapie infecting strain, as well as the time course of the disease, as previously underlined $[7,40]$.

Although the process of the retinopathy associated with the TSE has not been fully established, some mechanisms and hypotheses have been put forth. The current hypothesis, based on the study of the retina in sheep and hamsters with scrapie $[8,10,16,28,41]$ as well as in humans with sporadic and variant CJD [13,14], combined with the observation that the scrapie agent can be transported along a direct pathway from the superior colliculus to the retina [42], is that $\operatorname{PrP}^{\mathrm{Sc}}$ can spread from the brain to the retina via the optic nerve. Although immunoreactivity was not detected in the optic nerve of the current affected sheep, our observation that the histological changes were the most severe in the central and paracentral areas of the retina is in agreement with the hypothesis of neural spread. The possibility that scrapie infection spreads from the central nervous system to the retina by other modes of propagation, such as via the extracellular space or within and between glia, has not been ruled out [42]. Irrespective of the way the infection travels to the retina there is evidence that scrapie prions are present and replicate in the neurosensory retina prior to development of retinal lesions $[16,41,43]$. In the current study, $\operatorname{PrP}^{\mathrm{Sc}}$ accumulation was identified in all the scrapie retinas, and its localization within the retinal layers was in agreement with previous observations in sheep naturally [16] and experimentally [44] infected with scrapie. The presence of the $\mathrm{PrP}^{\mathrm{Sc}}$ in the plexiform layers, which are the high synaptic density areas of the retina, as seen in sheep with scrapie [16] and humans with CDJ [13], also argues for a centrifugal spread from the brain to the eye via the optic nerve [14]. The loss of cells contributing to the outer and inner nuclear layers of the retina in subjects with TSE presumably occurs by apoptosis in response to exposure to $\mathrm{PrP}^{\mathrm{Sc}}$ and/or its degradation products as found in the rat retina with the $\mathrm{PrP}^{\mathrm{Sc}}$ fragment P106126 [45]. Recent findings in sheep experimentally infected with scrapie demonstrate a decrease in immunoreactivity of specific markers of bipolar, ganglion and Müller cells [43]. These neuronal functions were impaired before the onset of microscopically retinal pathology was detected, suggesting that alterations in protein expression patterns in retinal cells might be one of the pathways for inducing retinal degeneration [43]. Gliosis is a fundamental response of the central nervous system to scrapie infection in sheep [40], and the current and previous findings $[16,43,45]$ demonstrate that it is a prominent pathological feature of the retinopathy in affected animals. The gliotic response of Müller cells is known to occur in various retinal diseases and may increase the susceptibility of neurons to stressful stimuli in the diseased retina [46]. In the case of ovine scrapie, whether the retinal gliosis participates in the death of neurons in the retina or is a secondary event resulting from the loss of the retinal neurons remains to be elucidated.

\section{Conclusion}

An extensive retinal degeneration was observed in all these ewes with naturally occurring scrapie although no clear visual impairment and no appreciable fundic alterations were observed in these animals. The characteristics of their ERGs indicated that both the rod and cones responses were significantly reduced in agreement with the retinal lesions which predominated in the outermost layers. Scrapie prion accumulation was present in all scrapie retinas, and both the marked loss of photoreceptors and bipolar cells and the strong $\operatorname{PrP}^{\mathrm{Sc}}$ 
staining within the central retina were consistent with a centrifugal spread of scrapie infectivity. One of the main problems with the TSE therapeutic trial is the quantitative characterization of the progression/regression of neurodegenerative process, in treated versus untreated individuals. In most of the cases, evaluation of therapeutic efficacy relies on the quantification of different lesions (neuronal loss/abnormal PrP accumulation) in tissues, which requires killing of the subjects. Because it is a non-invasive procedure that directly reflects neuroretinal degeneration, electrophysiological follow-up of the retinal function in TSE affected animal will warrant further studies to know if it may provide a reliable insight for monitoring evolution/regression of neurodegenerative changes in individuals.

\section{List of abbreviations}

BSE: Bovine spongiform encephalopathy; CJD: Creutzfeld-Jacob disease; ERG: Electroretinography; GFAP: Glial fibrillary acidic protein; INL: Inner nuclear layer; IPL: Inner plexiform layer; ONL: Outer nuclear layer; OPL: Outer plexiform layer; PrP: Normal prion protein; $\operatorname{PrP}^{\mathrm{Sc}}$ : Abnormal prion protein; TSE: Transmissible spongiform encephalopathies

\section{Acknowledgements}

- The authors are very grateful to Didier Concordet for assistance with the statistical analysis of the data. This study was supported by agreement A02507 with the Midi-Pyrénées region within the framework of a research programme on prions.

\section{Author details}

'UMR 181 Physiopathologie et Toxicologie Expérimentales, INRA, Ecole Nationale Vétérinaire, 23 chemin des Capelles, B.P. 87614, 31076 Toulouse Cedex 3, France. ${ }^{2}$ UMR 1225 Interactions Hôtes-Agents Pathogènes, INRA, Ecole Nationale Vétérinaire, 23 chemin des Capelles, B.P. 87614, 31076 Toulouse Cedex 3, France.

\section{Authors' contributions}

AR developed study design, contributed to ophthalmologic and electroretinographic investigations, performed analysis of ERG data, and took part in writing the manuscript. OAn performed histomorphometric and immunohistological examinations, and took part in writing the manuscript. OAl was involved in histomorphometric and immunohistological examinations. DC was involved in ophthalmologic and electroretinographic investigations. FS contributed to the study design and critically revised the manuscript. PLT contributed to the statistical analysis of the data and took part in writing the manuscript. All authors read and approved the final manuscript.

Received: 27 July 2010 Accepted: 6 June 2011 Published: 6 June 2011

\section{References}

1. Schreuder BEC: Animal spongiform encephalopathies: An update. part 1. Scrapie and lesser known animal spongiform encephalopathies. Vet $Q$ 1994, 16:174-181.

2. Prusiner SB: Natural and experimental prion diseases of humans and animals. Curr Opin Neurobiol 1992, 2:638-647.

3. Bolton DC, McKinley MP, Prusiner SB: Identification of a protein that purifies with the scrapie prion. Science 1982, 218:1309-1311.

4. Prusiner SB, Bolton DC, Groth DF, Bowman KA, Cochran SP, McKinley MP: Further purification and characterization of scrapie prions. Biochemistry 1982, 21:6942-6950.

5. Prusiner SB, DeArmond SJ: Molecular biology and pathology of scrapie and the prion diseases in humans. Brain Pathol 1991, 1:297-310.

6. Chow RL, Lang RA: Early eye development in vertebrates. Annu Rev Cell Dev Biol 2001, 17:255-296.
7. Hogan RN, Kingsbury DT, Baringer JR, Prusiner SB: Retinal degeneration in experimental Creutzfeldt-Jakob disease. Lab Invest 1983, 49:708-715

8. Buyukmihci N, Goehring-Harmon F, Marsh RF: Retinal degeneration during clinical scrapie encephalopathy in hamsters. J Comp Neurol 1982, 205:153-160.

9. Kozlowski PB, Moretz RC, Carp RI, Wisniewski HM: Retinal damage in scrapie mice. Acta Neuropathol 1982, 56:9-12.

10. Buyukmihci N, Goehring-Harmon F, Marsh RF: Retinal degeneration in experimental scrapie after intraperitoneal or subcutaneous inoculation of hamsters. Exp Neurol 1985, 88:461-466.

11. Curtis R, Fraser H, Foster JD, Scott JR: The correlation of electroretinographic and histopathological findings in the eyes of mice infected with the 79A strain of scrapie. Neuropathol Appl Neurobiol 1989, 15:75-89.

12. De Seze J, Hache JC, Vermersch P, Arndt CF, Maurage CA, Pasquier F, Laplanche JL, Ruchoux MM, Leys D, Destée A, Petit H: Creutzfeldt-Jakob disease: neurophysiologic visual impairments. Neurology 1998, 51:962-967.

13. Head MW, Northcott V, Rennison K, Ritchie D, McCardle L, Bunn TJR, McLennan NF, Ironside JW, Tullo AB, Bonshek RE: Prion protein accumulation in eyes of patients with sporadic and variant CreutzfeldJakob disease. Invest Ophthalmol Vis Sci 2003, 44:342-346.

14. Head MW, Peden AH, Yull HM, Ritchie DL, Bonshek RE, Tullo AB, Ironside JW: Abnormal prion protein in the retina of the most commonly occurring subtype of sporadic Creutzfeldt-Jakob disease. Brit J Ophthalmol 2005, 89:1131-1133.

15. Barnett KC, Palmer AC: Retinopathy in sheep affected with natural scrapie. Res Vet Sci 1971, 12:383-385.

16. Hortells $\mathrm{P}$, Monzón M, Monleón E, Vargas A, Bolea R, Luján L, Badiola JJ: Pathological findings in retina and visual pathways associated to natural scrapie. Brain Res 2006, 1108:188-194.

17. Smith JD, Greenlee JJ, Hamir AN, West Greenlee MH: Altered electroretinogram b-wave in a Sufflok sheep experimentally infected with scrapie. Vet Rec 2009, 165:179-181

18. Regnier A, Andreoletti O, Cayez D, Schelcher F, Toutain PL: Retinal pathology in natural cases of ovine scrapie. In Proceedings Notes of the American College of Veterinary Ophthalmologists (ACVO) 35th Annual Conference: 20-23 October 2004. Edited by: ACVO. Washington DC; 2004:78.

19. Narfström K, Ekesten B: Electroretinographic evaluation of Papillons with and without hereditary retinal degeneration. Am J Vet Res 1998, 59:221-226.

20. Healy AM, Weavers E, McElroy M, Gomez Parada M, Collins JD, O'Doherty E, Sweeney T, Doherty ML: The clinical neurology of scrapie in irish sheep. J Vet Intern Med 2003, 17:908-916.

21. Sokal RR, Rohlf FJ: Biometry: The principles and practice of statistics in biological research. New York: WH Freeman and Company; 21981.

22. Foster JD, Parnham D, Chong A, Goldmann W, Hunter N: Clinical signs, histopathology and genetics of experimental transmission of BSE and natural scrapie to sheep and goats. Vet Rec 2001, 148:165-171.

23. Benestad SL, Sarradin P, Thu B, Schönheit J, Tranulis MA, Bratberg B: Cases of scrapie with unusual features in Norway and designation of a new type, Nor98. Vet Rec 2003, 153:202-208.

24. Dagleish MP, Rodger SM, Simmons MM, Finlayson J, Buxton D, Chianini F: Atypical scrapie in a sheep in Scotland. Vet Rec 2008, 162:518-519.

25. Foster J, Toovey L, McKenzie C, Chong A, Parnham D, Drummond D, Hunter N: Atypical scrapie in a sheep in a closed UK flock with endemic natural scrapie. Vet Rec 2008, 162:723-725.

26. Mayhew IG, Jolly RD, Pickett BT, Slack PM: Ceroid-lipofuscinosis (Batten's disease): pathogenesis of blindness in the ovine model. Neuropathol Appl Neurobiol 1985, 11:273-290.

27. Van der Lugt JJ, Olivier J, Jordaan P: Status spongiosis, optic neuropathy, and retinal degeneration in Helichrysum argyrosphaerum poisoning in sheep and a goat. Vet Pathol 1996, 33:495-502.

28. Buyukmihci N, Goehring-Harmon F, Marsh RF: Photoreceptor degeneration in experimental transmissible mink encephalopathy of hamsters. Exp Neurol 1987, 96:727-731.

29. Nilsson SEG, Knave BG, Persson HE, Lunt T: The morphology of the sheep retina I. The receptor cells and the pigment epithelium. Acta Ophthalmol 1973, 51:599-611.

30. Smith EL, Witzel DA, Pitts DG: The waveform and scotopic CFF of the sheep electroretinogram. Vision Res 1976, 16:1241-1245. 
31. Graydon RJ, Jolly RD: Ceroid-lipofuscinosis (Batten's disease)-Sequential electrophysiologic and pathologic changes in the retina of the ovine model. Invest Ophthalmol Vis Sci 1984, 25:294-301.

32. Strain GM, Claxton MS, Prescott-Mathews JS, LaPhand DJ:

Electroretinogram and visual-evoked potential measurements in sheep. Can J Vet Res 1991, 55:1-4.

33. Hood D, Birch D: The a-wave of the human electroretinogram and rod photoreceptor function. Invest Ophthalmol Vis Sci 1990, 31:2070-2081.

34. Stockton RA, Slaughter MM: b-wave of the electroretinogram. A reflection of ON bipolar cell activity. J Gen Physiol 1989, 93:101-122.

35. Wen R, Oakley B II: $\mathrm{K}^{+}$evoked Müller cell depolarization generates bwave of electroretinogram in toad retina. Proc Natl Acad Sci USA 1990 87:2117-2121

36. Katz BJ, Warner JE, Digre KB, Creel DJ: Selective loss of the electroretinogram B-wave in a patient with Creutzfeldt-Jakob disease. $J$ Neuroophthalmol 2000, 20:116-118.

37. Gouras P: Electroretinography: some basic principles. Invest Ophthalmol Vis Sci 1970, 9:557-569.

38. Sandberg MA, Pawlyk BS, Berson EL: Full-field electroretinograms in miniature poodles with progressive rod-cone degeneration. Invest Ophthalmol Vis Sci 1986, 27:1179-1184.

39. Katz ML, Narfström K, Johnson GS, O'Brien DP: Assessment of retinal function and characterization of lysosomal storage body accumulation in the retinas and brains of Tibetan Terriers with ceroid-lipofuscinosis. Am J Vet Res 2005, 66:67-76.

40. Fraser H: Diversity in the neuropathology of scrapie-like diseases in animals. Br Med Bull 1993, 49:792-809.

41. Hogan RN, Bowman KA, Baringer JR, Prusiner SB: Replication of scrapie prions in hamsters eyes precedes retinal degeneration. Ophthalmic Res 1986, 18:230-235.

42. Fraser $\mathrm{H}$ : Neuronal spread of scrapie agent and targeting of lesions within the retino-tectal pathway. Nature 1983, 295:149-150.

43. Smith JD, Greenlee JJ, Hamir AN, West Greenlee MH: Retinal cell types are differentially affected in sheep with scrapie. J Comp Pathol 2008, 138:12-22.

44. Greenlee JJ, Hamir AN, West Greenlee MH: Abnormal prion accumulation associated with retinal pathology in experimentally inoculated scrapieaffected sheep. Vet Pathol 2006, 43:733-739

45. Ettaiche M, Pichot R, Vincent JP, Chabry J: In vivo cytotoxicity of the prion protein fragment 106-126. J Biol Chem 2000, 275:36487-36490

46. Bringmann A, Pannicke T, Grosche J, Francke M, Wiedemann P, Osborne NN, Reichenbach A: Müller cells in the healthy and diseased retina. Prog Retin Eye Res 2006, 25:397-424.

doi:10.1186/1746-6148-7-25

Cite this article as: Regnier et al: Clinical, electroretinographic and histomorphometric evaluation of the retina in sheep with natural scrapie. BMC Veterinary Research 2011 7:25.

\section{Submit your next manuscript to BioMed Central and take full advantage of:}

- Convenient online submission

- Thorough peer review

- No space constraints or color figure charges

- Immediate publication on acceptance

- Inclusion in PubMed, CAS, Scopus and Google Scholar

- Research which is freely available for redistribution 